\title{
FORMULATION AND DEVELOPMENT OF FLOATING DRUG DELIVERY OF ITOPRIDE HCL
}

\author{
Ratnaparkhi Mukesh P.*, Pawar Sham A., Somvanshi Fattesingh U., Chaudhari Shilpa P. \\ Department of Pharmaceutics, MarathwadaMitraMandal's College of Pharmacy, Thergaon (Kalewadi), Pune, India-411033
}

*Corresponding Author's E mail ID: mukeshparkhi@yahoo.co.in

\begin{abstract}
The aim of current research was to formulate floating tablets of Itopride hydrochloride using an effervescent approach for gastroretentive drug delivery system,as itisgastroprokinetic drug, the site of action is stomach and as the drug $\mathrm{pH}$ ranges from 3.5 to 5.5. It was formulated as hydrodynamic balanced tablet using sodium bicarbonate and citric acid as gas generating agent, HPMC as hydrophilic polymerand Xanthan gum as drug release retarding agent with an objective to control the drug release and restrict the region of drug release to stomach. Tablets were prepared by direct compression method. Drug Excipient compatibility study was confirmed by FTIR \& DSC studies.Floating tablets were prepared by direct compression using $3^{2}$ factorial design using different polymers as independent variables in which HPMC K4M, Xanthan gum were used for maintaining drug release and dependent variables as \% drug release, floating lag time \& swelling index. The floating tablet formulations were evaluated for physical characterization, assay, swelling index, in-vitro drug release, hardness, friability, weight variation.The formulations were investigated for \% drug release, floating lag time by in-vitro dissolution study. Formulation was optimized on basis of acceptable tablet properties and in vitro drug release. Formulation F1 was selected on basis of factorial design dependent variable i.e. \% drug release, floating lag time \& swelling index.

Keywords:Floating drug delivery system, Gastroprokinetic drug, Swelling index, HPMC K4M, Xanthan gum.
\end{abstract}

\section{INTRODUCTION}

Oral route is considered most natural, uncomplicated,convenient and safe due to its ease of administration, patient acceptance and cost-effective manufacturing process. Floating Drug Delivery Systems (FDDS) have a bulk density lower than gastric fluids and thus remain buoyant in the stomach for a prolonged period of time, without affecting the gastric emptying rate. This results in an increase in the Gastro Retentive Time and a better control of fluctuations in the plasma drug concentrations. ${ }^{1}$ Floating systems can be classified into two distinct categories, non-effervescent and effervescent systems. The gastric emptying time has been reported to be from 2-6h in humans in the fed state. When a sustained release dosage form is administered orally, sufficient bioavailability could not be obtained, especially for drugs having a limited absorption site in the intestinal tract. Therefore modern oral controlled release dosage forms must be based on gastrointestinal physiology, so that the drug is fully available for absorption ${ }^{2-3}$

\section{Stomach specific floating drug delivery}

Stomach Specific FDDS have a bulk density less than gastric fluids and so remain buoyant in the stomach without affecting the gastric emptying rate for a prolonged period of time. While the system is floating on the gastric contents, the drug is released slowly at the desired rate from the system. After release of drug, the residual system is emptied from the stomach. This results in an increased GRT and a better control of fluctuations in plasma drug concentration. The floating sustained release dosage forms present most of the characteristics of hydrophilic matrices and are known as 'hydrodynamically balanced systems' ('HBS') since they are able to maintain their low apparent density, while the polymer hydrates and builds a gelled barrier at the outer surface. The drug is released progressively from the swollen matrix. ${ }^{4-5}$

Itopride hydrochloride is a novel gastroprokinetic drug, widely absorbed from the stomach and upper part of the small intestine and absorption becomes less as the drug passes beyond this. The bioavailability can be improved by making the drug completely absorbed in the stomach and upper part of the small intestine. It has a half life of 6hrs. The short half life of Itopride hydrochloride necessitates frequent administration. Therefore it is highly desirable to have a controlled release dosage form for Itopride hydrochloride ${ }^{6}$

\section{Gastric emptying}

Gastric emptying occurs during fasting as well as fed states. The pattern of motility is however distinct in the 2 states. During the fasting state an interdigestive series of electrical events take place, which cycle both through stomach and intestine every $2-3$ hours. This is called the interdigestivemyloelectric cycle or migrating myloelectric cycle (MMC), which is further divided into following 4 phases as described by Wilson and Washington. PHASE I the quiescent period, lasts from 30 to 60 mins and is characterized by a lack of secretary, electrical and contractile activity. PHASE II, exhibits intermittent activity for $20-40 \mathrm{~min}$, during which the contractile motions increase in frequency and size. Bile enters the duodenum during this phase, whereas gastric mucus discharge occurs during the latter part of phase II and throughout phase III. PHASE III is a short period of intense large regular contractions, termed "housekeeper waves" that sweep off undigested food and last 10-20 min. PHASE IV is the transition period of $0-5$ mins between Phase III \& I . ${ }^{7-8}$

\section{Factors affecting gastric emptying}

The most important parameters affecting gastric emptying and, hence, the gastric retention time oforal dosage forms include:Density, Size, Shape of dosage form, Single or Multiple unit formulation, Fed or Unfed state, Nature of Meal Gender, Age ,Biological factors, Frequency of Feed etc ${ }^{9-10}$

In the present study HPMC K4M, Xanthan Gum, Sodium Bicarbonate, Citric acid, Lactose was used for formulating floating drug delivery system. When tablet reaches to gastric fluid, it floats due to effervescence produced by 
Ratnaparkhi et al

Journal of Drug Delivery \& Therapeutics; 2013, 3(4), 222-228

Sodium Bicarbonate \& Citric acid. Drug release controlled by HPMC K4M Xanthan Gum due to their swelling \&release retarding properties. The proposed formulation can be manufactured using currently available pharmaceuticaltechnology and materials recognized as safe.

\section{MATERIALS \& METHOD}

\section{Materials}

Itopride HCL was purchased from Leo Chem researcher resources Ltd. Bangalore (India). HPMC K4M and Xanthan gum were obtained From Research lab Fine chem. (India).Other excipientsused to prepare the tablets were either of analytical or pharmaceutical grades purchased from local market.

\section{Method}

\section{Drug Excipients Compatibility Study}

Sample of pure drug, physical mixture of excipients and drug in $(1: 1)$ ratio was placed at accelerated stability condition $40 \pm 2{ }^{\circ} \mathrm{C}$ and $75 \pm 5 \%$ relative humidity for a period of
3 month. At the end of 3 month samples were evaluated for drug-excipients compatibility using Differential scanning colorimeter (DSC) (Mettler Toledo DSC 822e, Japan) and Fourier transformed infrared spectroscopy (FT-IR) (Shimadzu Corporation, Japan, 8400s).

\section{Formulation of floating tablets}

Floating tablets of itopride hydrochloride were prepared by direct compression method. The composition of formulation is given in the Table 1 . Itopride $\mathrm{HCl}$, lactose and hydrophilic polymers were passed from sieve of \# 40 and mixed for $10 \mathrm{~min}$. All the Ingredients were weighed accurately.Itopride $\mathrm{HCl}$, lactose and hydrophilic polymers were passed from sieve of \# 40 and mixed for 10 min blended in glass mortar uniformly. Then remaining excipients were also passed sieve of \# 60 \& mixed with drug blend. After sufficient mixing, powder blend was compressed into tablets on a 12 station single punch rotary tablet compression machine. A concave faced punch $10 \mathrm{~mm}$ in diameter were used for tableting. Compression force of the machine was adjusted to obtain the hardness of $5 \mathrm{~kg} / \mathrm{cm} 2$ and $7 \mathrm{~kg} / \mathrm{cm} 2$ for different batches.

Table 1: Composition of all the formulations (Batch F1 - Batch F9)

\begin{tabular}{|l|l|l|l|l|l|l|l|l|}
\hline BATCH & ITOPRIDE & $\begin{array}{l}\text { HPMC } \\
\text { K 4M }\end{array}$ & $\begin{array}{l}\text { XANTHAN } \\
\text { GUM }\end{array}$ & NaHCO3 & $\begin{array}{l}\text { CITRIC } \\
\text { ACID }\end{array}$ & LACTOSE & $\begin{array}{l}\text { Mg. } \\
\text { STERATE }\end{array}$ & TOTAL \\
\hline F1 & 100 & 120 & 50 & 100 & 70 & 106 & 4 & 550 \\
\hline F2 & 100 & 120 & 70 & 100 & 70 & 86 & 4 & 550 \\
\hline F3 & 100 & 120 & 90 & 100 & 70 & 66 & 4 & 550 \\
\hline F4 & 100 & 140 & 70 & 100 & 70 & 66 & 4 & 550 \\
\hline F5 & 100 & 140 & 50 & 100 & 70 & 86 & 4 & 550 \\
\hline F6 & 100 & 140 & 90 & 100 & 70 & 46 & 4 & 550 \\
\hline F7 & 100 & 160 & 50 & 100 & 70 & 66 & 4 & 550 \\
\hline F8 & 100 & 160 & 70 & 100 & 70 & 46 & 4 & 550 \\
\hline F9 & 100 & 160 & 90 & 100 & 70 & 26 & 4 & 550 \\
\hline
\end{tabular}

\section{$3^{2}$ Full Factorial Design}

A $\mathbf{3}^{2}$ randomized full factorial design was used in this study. In this design 2 factors were evaluated, each at 3 levels, and experimental trials were performed at all 9 possible combinations. The amount of HPMC(X1) and Amount of Xanthan Gum (X2) were selected as independent variables. The times required to float, swelling index \& $\%$ release were selected as dependent variables. The experimental design with corresponding formulation outline in Table 2.

Table 2: Composition of formulations

\begin{tabular}{|l|l|l|}
\hline Batch code & X1 & X2 \\
\hline F1 & -1 & -1 \\
\hline F2 & -1 & 0 \\
\hline F3 & -1 & 1 \\
\hline F4 & 0 & 0 \\
\hline F5 & 0 & -1 \\
\hline F6 & 0 & 1 \\
\hline F7 & 1 & -1 \\
\hline F8 & 1 & 0 \\
\hline F9 & 1 & 1 \\
\hline
\end{tabular}

\begin{tabular}{|l|l|l|}
\hline Levels & Amount of HPMC (X1) & Amount of Xanthan Gum (X2) \\
\hline-1 & 120 & 50 \\
\hline 0 & 140 & 70 \\
\hline 1 & 160 & 90 \\
\hline
\end{tabular}




\section{EVALUATION}

\section{Thickness:}

Thickness of tablets was determined using Vernier caliper. Five tablets from batch wereused, and average values were calculated..$^{11-12}$

\section{Weight variation test}

To determine average weight, each tablet from formulation was weighed using an electronic balance (AUX220, Shimadzu). ${ }^{11-12}$

\section{Hardness:}

The hardness was tested using Monsanto tester. The force is measured in kilograms. ${ }^{\mathbf{1 1 - 1 2}}$

\section{Friability:}

For each formulation, the friability of 6 tablets was determined using the Roche friabilator (Lab Hosp.). ${ }^{11-12}$

\section{In vitro drug release study of floating tablets}

In-vitro dissolution studies were performed on floating tablets prepared by direct compression method using $0.1 \mathrm{~N}$ HCL for $12 \mathrm{hrs}$. USP apparatus II with the paddle speed $50 \mathrm{rpm} .1 \mathrm{ml}$ of filtered aliquot was withdrawn at predetermined time intervals and replaced with $1 \mathrm{ml}$ maintained at the same temperature. The samples were analyzed at 258 $\mathrm{nm}$ using a UV spectrophotometer. The floating lag time and percentage release was determined for the each formulation. . $^{13-14}$

\section{RESULT AND DISCUSSION:}

\section{Compatability study}

\section{Drug-Excipient Interactions:}

The IR spectra of Formulation were compared with the standard spectrum of Itopride HCL (Fig. 1). IR spectrum of was Itopride HCL characterized by the absorption of$\mathrm{C}=\mathrm{O}$ group at $1662 \mathrm{~cm}-1,-\mathrm{OCH}_{3}$ group at $1128 \mathrm{~cm}-1 \& \mathrm{~N}-$ $\mathrm{H}$ Stretching at $3281 \mathrm{~cm}-1$. In spectra of Formulation,band was same absorption pattern as that of pure drug. Mentioned evidences thus lead to the conclusion that changes were not seen as there was no physical interaction between the drug and polymers.

In DSC study also drug was characterized by its melting point $\&$ formulation was also showing same results as drug, by these mentioned evidences lead to the conclusion that changes were not seen $\mathrm{s}$ there was no physical interaction between the drug \&polymers (Fig 2).
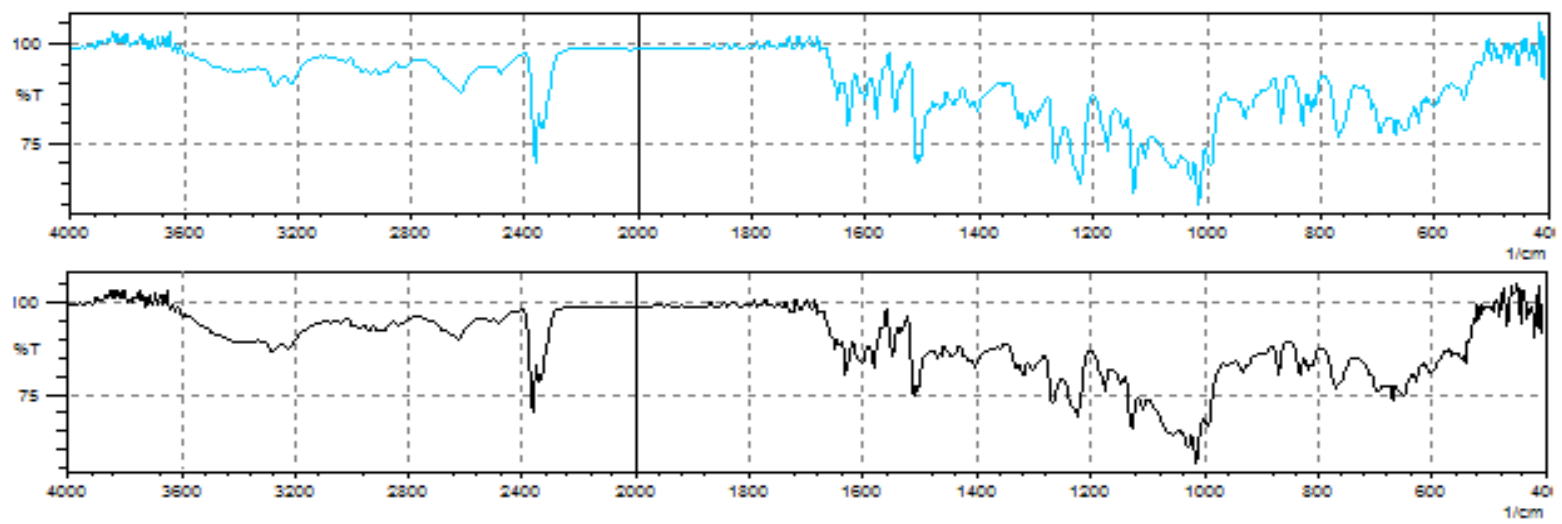

Figure 1: IR Spectrogram of Drug ItoprideHcl\& formulation

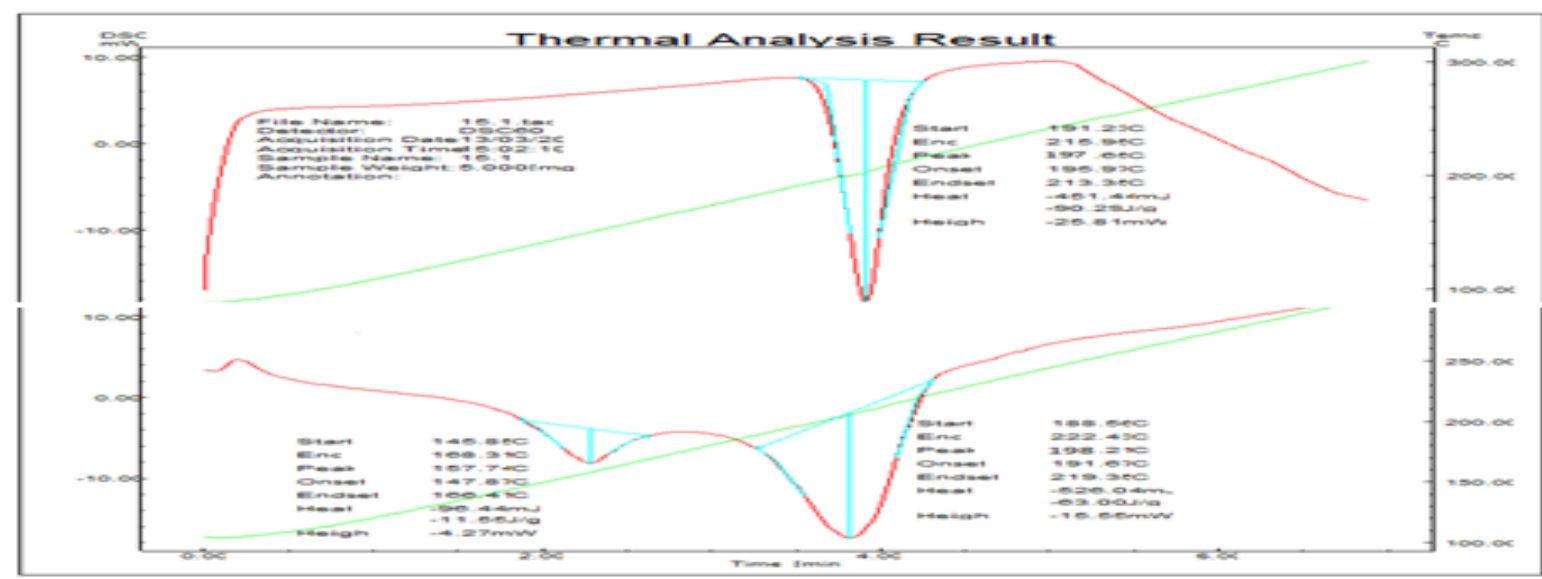

A

B

Figure 2: DSC Spectrogram of Drug ItoprideHcl (A) \& formulation (B)

\section{Preparation of floating tablets}

Floating tablets were prepared by using 2 independent variables as different concentrations of polymers by using $3^{2}$ factorial design. In formulation excipients used were HPMC K4M, Xanthan Gum, Sodium bicarbonate, Citric Acid, lactose \& Magnesium Sterate. Carbon dioxide is formed within the tablet containing effervescent agent when the tablet is brought in contact with the acidic dissolution medium. Sodium bicarbonate is used 
as gas generating agent which induces floatability of the tablet and it makes tablet remain to float in stomach The low density of hydroxypropyl methylcellulose assists in floating the tablet. Moreover, the gelling capacity of HPMC also helps to float the tablet by entrapping carbon dioxide gas in the gel network of HPMC. The gelling capacity of HPMC prevents disintegration of the tablet during the dissolution study. HPMC was choosen as swellable polymer because it is widely used as low-density hydrocolloid system, upon contact with water a hydrogel layer would be formed to act as a gel boundary for the delivery system, but it would fail to retard the release of drug through the matrix because of its solubility in stomach $\mathrm{pH}$. Xanthan gum is used in combination with HPMC to slow the drug release; xanthan gum ability to do this may be caused by the low solubility in gastric pH. Lactose is used as filler. Mg. stearate is used as lubricant and glidant to improve flow property of powder blend. Swelling index describes the amount of water that is contained within the hydrogel at equilibrium and is a function of the network structure, hydrophilicity and ionization of the functional groups.

\section{Precompression Parameters:}

Angle of repose $(\theta)$ : The values obtained for angle of repose for all formulations were tabulated in Table no.3The values were found to be in the range from $23^{\circ} .30^{\prime}$ to $28^{\circ} .88^{\prime}$. This indicates good flow property of the powder blend for direct compression.

Compressibility index: The values obtained for Compressibility index for all formulations were tabulated in Table no.3 Compressibility index value ranges between $11.23 \%$ to $18.45 \%$ indicating that the powder blend have the required flow property.

\section{Postcompression parameters}

\section{Tablet dimensions}

The dimensions determined for formulated tablets were tabulated in Table No.4. Tablets mean thickness $(n=3)$ were almost uniform in all the ten formulations and were found to be in the range of $5.12 \mathrm{~mm}$ to $5.18 \mathrm{~mm}$. The diameter of the tablet ranges between $10.00 \mathrm{~mm}$ to $10.03 \mathrm{~mm}$.

Table 3: Pre-compression parameters

\begin{tabular}{|c|c|c|}
\hline Batch & $\begin{array}{c}\text { Angle of Repose } \\
(\theta)\end{array}$ & Compressibility Index (\%) \\
\hline F1 & 24.49 & 13.34 \\
\hline F2 & 23.30 & 12.98 \\
\hline F3 & 27.12 & 12.30 \\
\hline F4 & 27.89 & 16.29 \\
\hline F5 & 28.31 & 18.45 \\
\hline F6 & 28.88 & 11.23 \\
\hline F7 & 25.09 & 12.67 \\
\hline F8 & 27.34 & 14.30 \\
\hline F9 & 24.22 & 15.33 \\
\hline
\end{tabular}

\section{Hardness test}

The measured hardness of tablets of each batch ranged between 5.5 to $6.5 \mathrm{~kg} / \mathrm{cm} 2$ (Table No.4). This ensures good handling characteristics of all batches.

\section{Friability test}

The values of friability test were tabulated in Table No.4. The $\%$ friabilitywas less than $1 \%$ in all the formulationsensuring that the tablets weremechanically stable.

\section{Weight variation test}

The percentage weight variations for all formulations were shown in Table No.4. All the tablets passed weight variation test as the \% weight variation was within the Pharmacopoeial limits of $\pm 5 \%$ of the weight. The weights of all the tablets were found to be uniform with low standard deviation values.

Table 4: Postcompression parameters

\begin{tabular}{|c|c|c|c|c|c|}
\hline Batches & $\begin{array}{c}\text { Diameter } \\
(\mathbf{m m}) \mathbf{n}=\mathbf{3}\end{array}$ & $\begin{array}{c}\text { Thickness(mm) } \\
\mathbf{n = 3}\end{array}$ & $\begin{array}{c}\text { Hardness(Kg/cm2) } \\
\mathbf{n = 3}\end{array}$ & $\begin{array}{c}\text { Friability(\%) } \\
\mathbf{n = 1 0}\end{array}$ & $\begin{array}{c}\text { Weight Variation } \\
(\mathbf{m g}) \mathbf{n = 2 0}\end{array}$ \\
\hline F1 & $10.00 \pm 0.034$ & $6.04 \pm 0.012$ & 5.5 & 0.78 & $551 \pm 1.29$ \\
\hline F2 & $10.01 \pm 0.023$ & $6.04 \pm 0.009$ & 6.5 & 0.71 & $550 \pm 1.37$ \\
\hline F3 & $10.01 \pm 0.045$ & $6.03 \pm 0.002$ & 6.5 & 0.70 & $550 \pm 1.33$ \\
\hline F4 & $10.01 \pm 0.052$ & $6.02 \pm 0.005$ & 6.0 & 0.89 & $549 \pm 1.22$ \\
\hline F5 & $10.02 \pm 0.024$ & $6.03 \pm 0.009$ & 5.5 & 0.77 & $552 \pm 1.21$ \\
\hline F6 & $10.00 \pm 0.039$ & $6.02 \pm 0.008$ & 6.5 & 0.91 & $550 \pm 1.19$ \\
\hline F7 & $10.00 \pm 0.048$ & $6.04 \pm 0.003$ & 6.0 & 0.85 & $551 \pm 1.23$ \\
\hline F8 & $10.02 \pm 0.021$ & $6.03 \pm 0.010$ & 6.5 & 0.79 & $550 \pm 1.49$ \\
\hline F9 & $10.01 \pm 0.046$ & $6.04 \pm 0.011$ & 5.5 & 0.80 & $551 \pm 1.19$ \\
\hline
\end{tabular}

\section{Swelling Study}

The swelling behavior of a dosage form was measured by studying its weight gain or water uptake.The dimensional changes could be measured in terms of the increase in tablet diameter and/or thickness over time. Water uptake was measured in terms of per cent weight gain, as given by the equation.

$$
\text { Swelling index }=\frac{W 2-W 1}{W 1} \times 100
$$

$\mathrm{W} 2=$ Weight of dosage form at time $\mathrm{t}$.

$\mathrm{W} 1$ = Initial weight of dosage form

From the following graph, it was concluded that as the time increases $\%$ swelling also increases. 


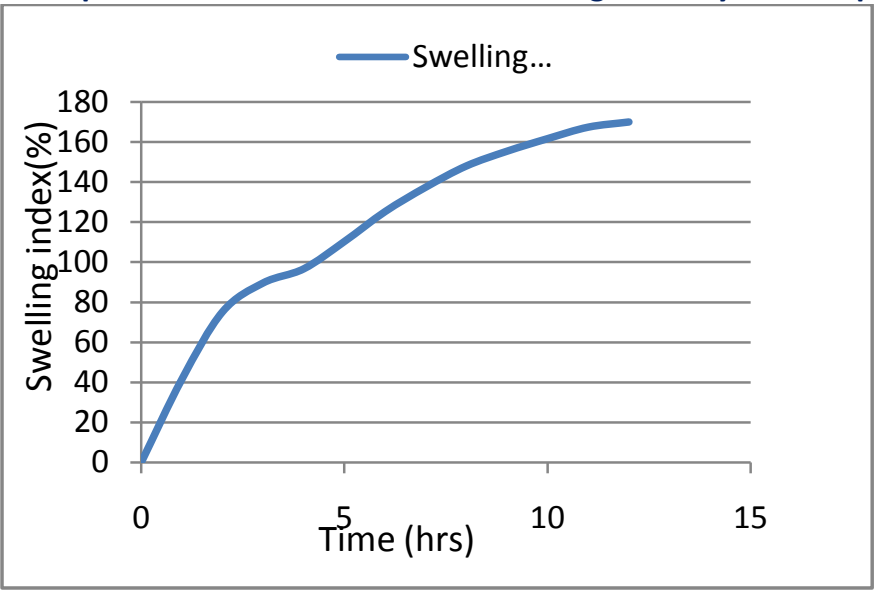

Figure 3: Plot of swelling index against time of optimized formulation $\mathrm{F} 1$

\section{Buoyancy study:}

On immersion in $0.1 \mathrm{~N} \mathrm{HCl}$ solution $\mathrm{pH}(1.2)$ at $37^{\circ} \mathrm{C}$, the tablets floated, and remained buoyant without disintegration. Fig.4 showed the results of buoyancy study and showed buoyancy character of prepared tablet of formulation. Formulation F1 shows floating lag time as $78 \mathrm{sec}$. which was less compared to other formulations.

\section{Drug content uniformity}

The percentage of drug content was found to be between $97.01 \%$ and $99.82 \%$ of Itopride hydrochloride, which was within acceptable limits. Table No. 5 showed the results of drug content uniformity in each batch.

\section{Effect of hardness on floating lag time:}

The effect of hardness on floating lag time for batch F1was studied. The results of floating lag time of tablet having hardness of $5.5 \mathrm{~kg} / \mathrm{cm} 2,6.5 \mathrm{~kg} / \mathrm{cm} 2$ and $7.5 \mathrm{~kg} / \mathrm{cm} 2$ were $78 \mathrm{sec}, 95 \mathrm{sec}$ and $120 \mathrm{sec}$ respectively as tabulated in Table 6. Batch F1 was selected for the study because it showed floating lag time of $78 \mathrm{sec}$ at hardness of 5.5 $\mathrm{kg} / \mathrm{cm} 2$. From this study we can conclude that as hardness increases, floating lag time also increases.

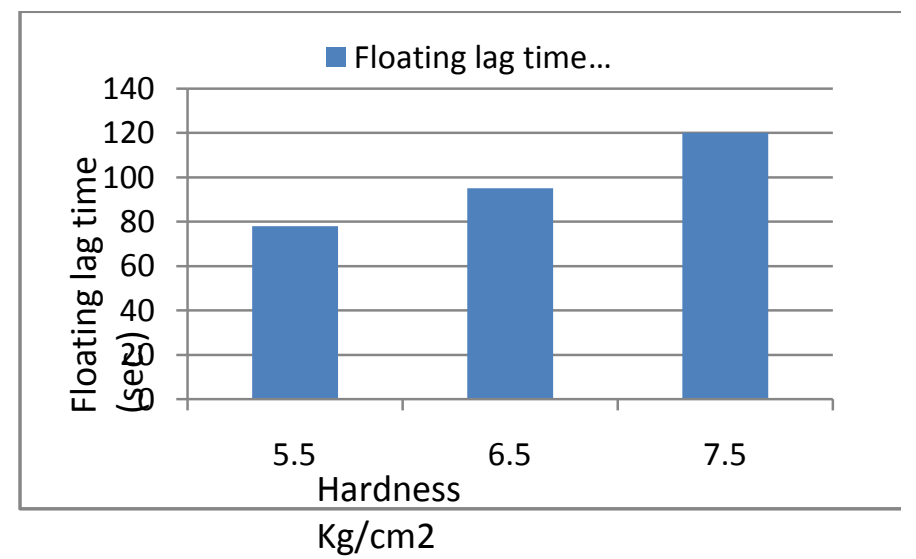

Figure.5: Plot of Floating lag time vs. Tablet hardness
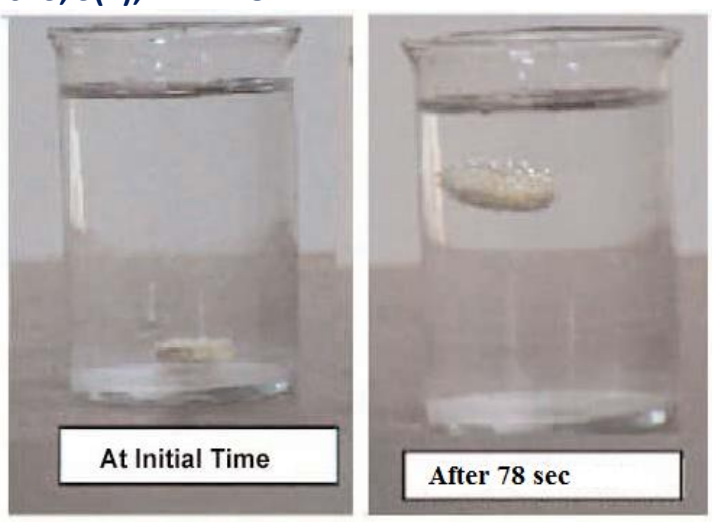

Figure 4:In vitro buoyancy study of batch F1.

Table 5: Drug content uniformity of tablets of batch F1 to F9

\begin{tabular}{|l|l|}
\hline \multicolumn{1}{|c|}{ Batches } & Drug content uniformity (\%) \\
\hline F1 & 99.03 \\
\hline F2 & 98.53 \\
\hline F3 & 97.89 \\
\hline F4 & 98.08 \\
\hline F5 & 99.01 \\
\hline F6 & 96.89 \\
\hline F7 & 97.33 \\
\hline F8 & 96.89 \\
\hline F9 & 95.09 \\
\hline
\end{tabular}

Table 6: Effect of Hardness on Buoyancy Lag Time of Batch $\mathrm{F} 1$

\begin{tabular}{|l|l|}
\hline \multicolumn{1}{|c|}{ Hardness } & Floating lag time \\
\hline $5.5 \mathrm{~kg} / \mathrm{cm} 2$ & $78 \mathrm{sec}$ \\
\hline $6.5 \mathrm{~kg} / \mathrm{cm} 2$ & $95 \mathrm{sec}$ \\
\hline $7.5 \mathrm{~kg} / \mathrm{cm} 2$ & $120 \mathrm{sec}$ \\
\hline
\end{tabular}

\section{Effect of conc of sodium bicarbonate and citric acid on floating lag time:}

The effect of conc of sodium bicarbonate and citric acid on buoyancy lag time for batch F1was studied. The results of floating lag time of tablet having conc sodium bicarbonate $60 \mathrm{mg}, 80 \mathrm{mg}, 100 \mathrm{mg}$ and citric acid $50 \mathrm{mg}, 60 \mathrm{mg}, 70 \mathrm{mg}$ was had floating lag time $120,90,78 \mathrm{sec}$ respectively as tabulated in Table 7 . The plot of floating lags time (sec) vs. conc of sodium bicarbonate and citric acid is depicted in Fig. 2 Batch F1 was selected for the study because it showed buoyancy lag time of $78 \mathrm{sec}$ at conc of sodium $100 \mathrm{mg}$ and citric acid $70 \mathrm{mg}$. From this study we can conclude that as conc of sodium bicarbonate and citric acid increases, floating lag time also decreases. 
Table no.7: Effect of conc of sodium bicarbonate and citric acid on floating lag time

\begin{tabular}{|l|l|l|}
\hline $\begin{array}{l}\text { Sodium bicarbonate } \\
(\mathbf{m g})\end{array}$ & $\begin{array}{l}\text { Citric } \\
\text { acid(mg) }\end{array}$ & $\begin{array}{l}\text { Floating lag } \\
\text { time (sec) }\end{array}$ \\
\hline 60 & 50 & 120 \\
\hline 80 & 60 & 90 \\
\hline 100 & 70 & 78 \\
\hline
\end{tabular}

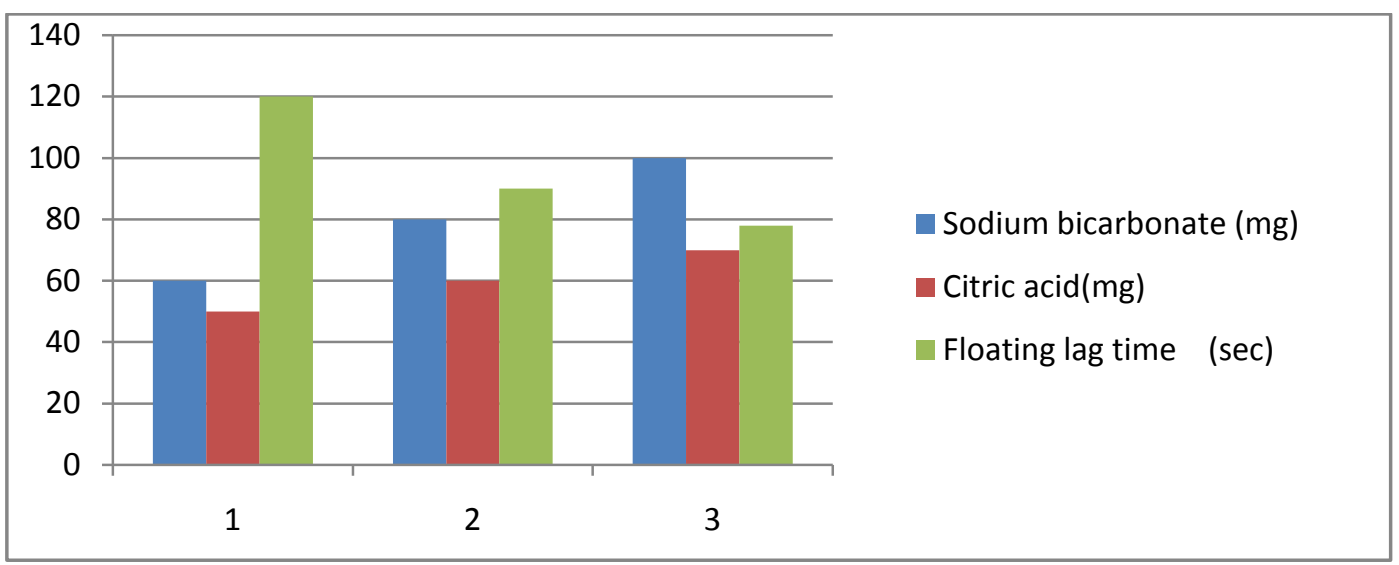

Figure 6: Effect of conc of sodium bicarbonate and citric acid on floating lag time

\section{In vitro drug release study of floating tablets}

From following graphs, we can observe that F1 formulation shows maximum drug release( $99.40 \%)$ compared to other formulations.

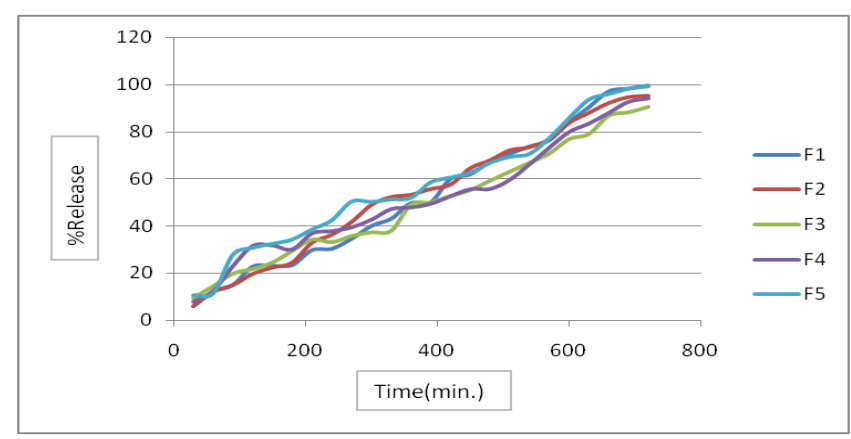

Figure 7: In vitro dissolution profile of formulations F 1 to F 5

\section{Data fitting to the model}

A two-factor, three-level optimal design as the response surface methodology (RSM) provides 9 runs. All the responses observed for 9 formulations were fitted to main effect model when using Design Expert (State ease Ver. 8.0.7.1) and the values of $\mathrm{R}^{2}$ and standard deviation are given in Table along with the regression equation generated for each response. Only statistically significant $(p<0.05)$ coefficients are included in the equations.

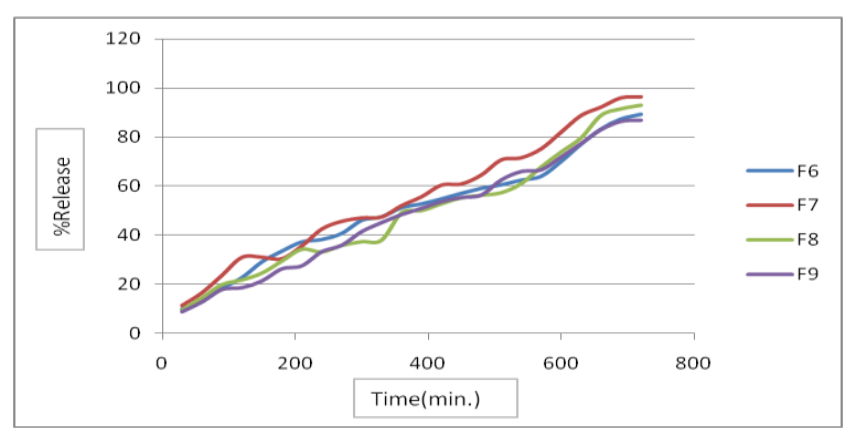

Figure 8: In vitro dissolution profile of formulations $\mathrm{F} 6$ to F 9

Table 8:Summary of Results of Regression Analysis for Response Y1, Y2, Y3

\begin{tabular}{|l|l|l|l|l|l|l|l|l|}
\hline Response & Models & F value & Prob $>$ F & $\mathbf{R}^{\mathbf{2}}$ & Adjusted R & Predicted R & S.D. $^{\mathbf{2}}$ & Remarks $^{2}$ \\
\hline Y1(Lag time) & Mean & 40.33 & 0.0017 & 0.9758 & 0.9516 & 0.8775 & 4.47 & Suggested \\
\hline Y2(\% release) & Mean & 39.00 & 0.0018 & 0.9750 & 0.9500 & 0.8734 & 0.91 & Suggested \\
\hline Y3(Swelling Index) & Mean & 47.68 & 0.0013 & 0.9837 & 0.9649 & 0.8952 & 1.62 & Suggested \\
\hline $\begin{array}{l}\text { Equations: } Y 1=105-9.56 X 1-1.46 X 2-20.22 X 1 X 2 \\
\text { Y2 }=93.69+1.56 X 1+1.44 X 2+2.47 X 1 X 2 \\
Y 3=185.78-13.78 X 1-2.37 X 2+1.04 X 1 X 2\end{array}$ \\
\hline
\end{tabular}




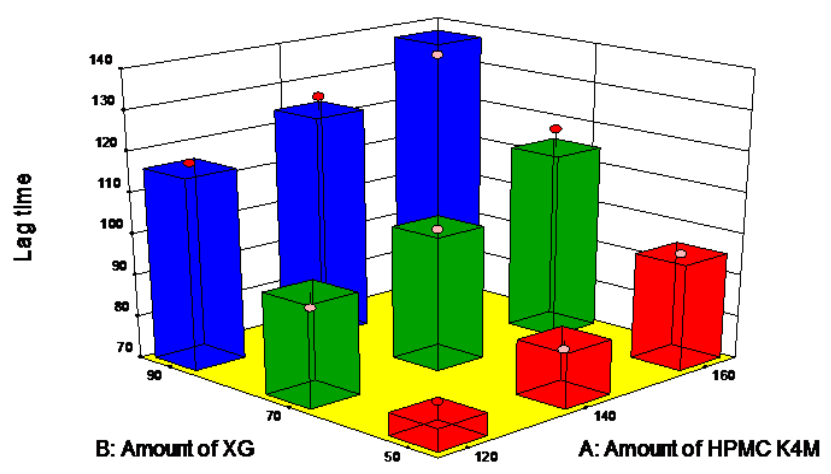

Figure 9: Effect of Xanthan gum \& HPMC K4M on lag time

From above graph we can observe that, as concentration of xanthan gum and HPMC K4M increases, floating lag time also increases.So concentration of xanthan gum $50 \mathrm{mg}$ and HPMC K4M $120 \mathrm{mg}$ shows less floating lag time as compared to other concentrations.

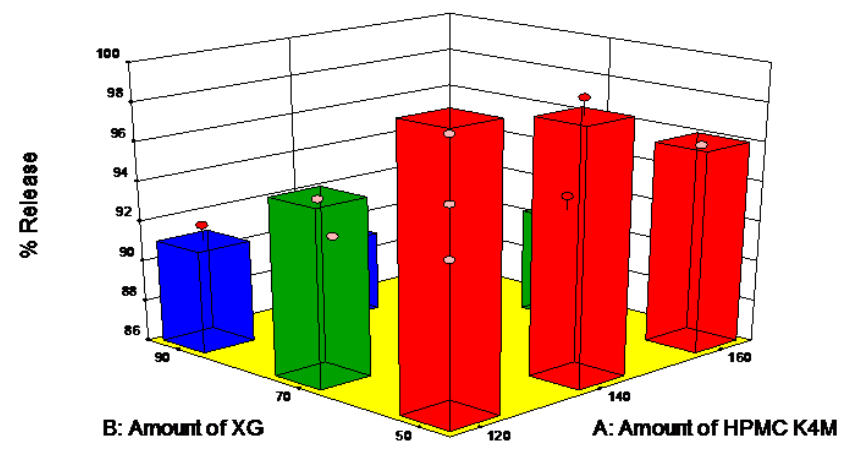

Figure 10: Effect of Xanthan gum \& HPMC K4M on \% Release

From above graph we can observe that, as concentration of xanthan gum and HPMC K4M increases, \% release of drug decreases. So concentration of xanthan gum $50 \mathrm{mg}$ and

\section{REFERENCES}

1. Moes AJ. Gastroretentive dosage forms. Crit Rev Ther Drug Carrier Syst 1993;10(2): 193-195.

2. Deshpande AA, Shah NH, Rhodes CT, Malick W. Development of a novel controlled release system for gastric retention. Pharm. Res. 1997; 14(6): 815-819.

3. Shah S.H, Patel J.K and Patel N.V., Stomach specific drug delivery systems: A review ,International Journal of PharmTech ResearchVol.1, No.3. 2009; 623-633.

4. Wilson CG, Washington N. The stomach: its role in oral drug delivery. In: Rubinstein MH, ed. Physiological Pharmacetical: Biological Barriers to Drug Absorption. Chichester, UK: Ellis Horwood; 1989:47-70.

5. Garg S, Sharma S.; Gastroretentive drug delivery systems; Pharmatech. 2003; 160-164.

6. Gupta S., Kapoor V., Kapoor B., DRUG REVIEW :Itopride ; A Novel Prokinetic Agent, JK SCIENCE 6(2) (2004).

7. Torotora GJ, Grabowski SR. Principles of anatomy and physiology. 10th Ed. New York: John Willey and Sons; 2002.
HPMC K4M $120 \mathrm{mg}$ shows more \% release of drug as compared to other concentrations.

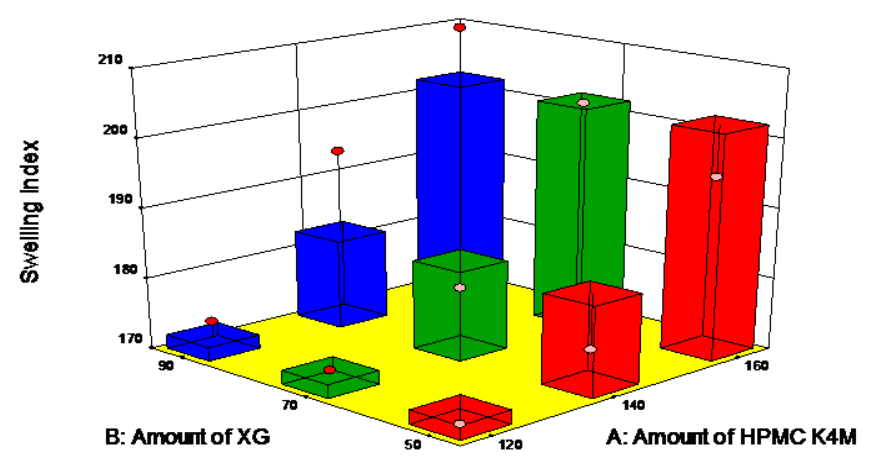

Figure 11: Effect of Xanthan gum \& HPMC K4M on Swelling index

From above graph we can observe that, as concentration o HPMC K4M increases, swelling index also increases. So concentration of HPMC K4M $120 \mathrm{mg}$ shows less swelling index as compared to other concentrations.

\section{CONCLUSION}

A lesser floating time and prolonged floating duration could be achieved by varying amount of effervescent mixture that is sodium bicarbonate and citric acid along with different polymer concentrations. The results of current study clearly indicate that the in vitro release of Itopride is significantly affected by the amount of HPMC $\mathrm{K} 4 \mathrm{M}$ and Xanthan gum .HPMC K4M and Xanthan gum in combination help in maintaining the matrix integrity of the tablets. As the concentration of HPMC K4M and Xanthan gum increases the drug release decreases significantly; polymers concentration affects the drug release rate. The HPMC K4M and Xanthan gum in combination can be promising polymers for gastro retentive drug delivery system. The optimized formulation of batch F1 gave the best in vitro release of $99 \%$ in 12 hrs.in simulated gastric fluid.

8. Caldwell LJ, Gardner RC, Cargill RC. Drug delivery device which can be retained in the stomach for a controlled period of time. US Patent 1998; 30th August: 4,767,627

9. Timmermans J, Gansbeke VB, Moes AJ. Assessing by gamma scintigraphy the in vivo buoyancy of dosage forms having known size and floating force profiles as a function of time. Vol I. Proceedings of the $5^{\text {th }}$ International Conference on Pharmacy Technology. Paris, France: APGI; 1989:42-51

10. Rahman Z, Khar RK. Design and Evaluation of Bilayer Floating Tablets of Captopril. ActaPharma; 2006:56; p49-57.

11. Liberman H.A, Lachman L, Schwartz J. B. Pharmaceutical Dosage Forms: Tablets. 1990; vol.-I 131-188.

12. Liberman H. A, Lachman L, Schwartz J. B. Pharmaceutical Dosage Forms: Tablet. 1990; vol.- II 2nd edition 1-104, 201-338.

13. Varshosaz J, Tavakoli N. Formulation and In Vitro Characterization of Captopril Floating Extended Release Tablet. Drug Delivery; 2006:13; p277-285.

14. Desai S, Bolton S. A floating controlled release system: In-vitro In-vivo evaluation. Pharm. Res. 1993; 10: 1321-1325. 